\title{
Biology and Predation Efficiency of the Spider Oecobius tembili Camrage (Araneida: Oecobiidae) Fed on the Cotton Leaf Worm Spodoptera litoralis (Boisd.)
}

\author{
Amal H.M. Romeih ${ }^{\star}$; M. H. El- Erkosousy ${ }^{\star *}$ and A. K. Aiad ${ }^{\star *}$ \\ "Agric. Zool. Dept., Fac. Agric. Cairo University, Giza, Egypt \\ ** Plant Protection Research Institute, Agriculture Research Center, Dokki, Giza, Egypt
}

\begin{abstract}
The spider Oecobius tembli was reared on first instar larvae of the cotton leafworm, Spodoptera littoralis (Boisd.). Incubation period averaged 7.3 days for both sexes at $30^{\circ} \mathrm{C}$. Both pass through five spiderlings before reaching adult stage. The life cycle averaged 52.6 and 47.8 days for female and male, respectively. Oviposition period avcraged 4.5 days, during which female deposited an average of 1.5 egg sacs. The Total number of consumed prey averaged 269.4 and 230.3 individuals for spider female and male, respectively.
\end{abstract}

Key Words: Biology, Oecobius tembli, Oecobiidae, Araneida.

\section{INTRODUCTION}

Spiders have always been known to be effective predators, though their potentials as biocontrol agents have not been exploited to its fullest, at least in Egypt. In addition, spiders have been found to be the most abundant group of predators in the cotton ecosystem (Riechert and Lockley, 1984).

Members of the family Oecobiidae are small to moderate size. They are usually found hanging upside driwn in an irregular web suspended on plants or hidden in rock crevices or fissures in soils (Levy, 1998). The present work throws, light for the first time on the biological aspects and predation efficiency of the oecobiid spider Oecobius tembli.

\section{MATERIALS AND METHODS}

Egg masses of the cotton leaf worm, $S$. littoralis were maintained until hatching. Newly hatched larvae were reared on leaves of castor plant, Ricinus communis in clean glass and successive cultures of $1^{\text {st }}$ and $2^{\text {nd }}$ instars larvae were used as prey.

\section{Rearing technique:}

Oecobius tembli i: dividuals were collected from clover,cotton and maize fields at Qalubiya, Kafr El-Sheikh and Beni-sueif governorates by using sweeping or directly from maize plants. Identification took place in the laboratory by helping of steriobinocular microscope using taxonomic key of Dick Jones, 1983.Newly emerged adult female and male were confined together in a test tube (20 $\mathrm{cm}$ long and $0.5 \mathrm{~cm}$ in diameter), closed with cotton pad and supplied daily with preys. The female was noticed daily until laying the egg sac and hatched spiderlings. Each spiderling was kept in a test tube together with surplus prey individuals and noticed till reaching adult stage. $1^{\text {st }}$ and $2^{\text {nd }}$ larval instars of the cotton leafworm, Spodoptera littoralis (Boisd.) were used as food through the spider life span. The numbers of consumed prey individuals were recorded daily and replaced by fresh ones. Behaviour and some biological aspects were also recorded.Experiment was carried out under laboratory conditions $\left(30 \pm 2^{\circ} \mathrm{C}\right.$ and $70 \pm 5$ R.H.\%).

\section{RESULTS AND DISCUSSION}

\section{Feeding behavior:}

When the predator $O$. tembli notices the prey, it usually comes close and moves around it for few seconds, then catches it between its chelicerae by the help of the front legs. Embeding its chelicerae in the prey,the predator starts to suck prey contents till leaving it as exuvium. The predator abdomen becomes enlarged and usually rests for few minutes before searching again for another one. No differences in feeding behavior were noticed when spider fed on the three tested preys.

\section{Mating behavior: \\ 1-Preparing period}

The virgin female stayed for about 5 days as a premating period. The male was firstly placed in the test tube, and then followed by the female. The latter started to come close to the male in relative movements for about 2 minutes. The male came close to it, moving his front legs up and down and pedipalps alternatively. It then touched the tips of the female legs and pidipalps, before the beginning of copulation.Both sexes must pass through the preparing period before copulation occurs, otherwise, the female refuses the male, 
threatening by its chelicerae to enforce the male to move away.

\section{2-Copulation}

The male holds the female using its first pair of legs; leg I to hold her leg II, and his leg II to hold her leg III, then inserts his right palp into the female genital opening. The sperms are transferred to female seminal receptacles. The mating process continued for about 1-2 minutes, then the male escaped away.

\section{Development and adult longevity:}

\section{Spiderling duration and food consumption}

Each of the spider female and male has five stages (spiderlings).The fifth spiderling was shorter in duration than other ones in both female and male, averaging 4.5 and 2.7 days ,respectively (Table 1 ) The duration of $1^{\text {st }}, 2^{\text {nd }}, 3^{\text {rd }}, 4^{\text {th }}$ and $5^{\text {th }}$ spiderlings averaged $8.4,9.9,15.9,6.6$ and 4.5 days for female and $8.4,9.4,14.6,5.4$ and 2.7 days for male , respectively Total female spiderling had longer duration (45.3 days) compared with the total male spiderlings, 40.5 days.

The food consumption of the spiderlings increased with its growth as shown in table 1 . The first stage of both female and male had the least prey consumption than the other stages spiderlings because of its small size, as it consumed about 78.4 and 66.3 preys/spiderling for female and male,respectively .The value gradually increased depending on the stage growth, for example the second spiderling consumed about 101.1 and 96.2 prey spiderlings/day for female and male respectively. On the other hand, the fifth spiderling consumed about 84.0 and 80.2 preys for female and male, respectively . As tabulated in table 1, female consumed more prey spiderlings/ day than male during all the stages. The total food consumption of the female spiderlings was 597.5 preys; while that of male was 649.1 preys.

\section{Female longevity}

The post ovipostion period of the spider female averaged 6 days as shown in table 2 during which the female consumed the least number of prey (105.8 spiderlings/day) compared with that consumed in the pre-oviposition and ovi-position periods.

The female stopped its feeding about one day at last of the pre-ovipostion then began to web the egg sac by her spinnerets, deposited the eggs and covered it by layer of dense silky webbing. The ovipostion period durated about 4.5days and the food consumption increased (128 prey spiderling/day) compared with the rates of pre-oviposition and post-oviposition .During the three periods, the spider female consumed a total of 365.7 prey spiderlings.

\section{Eggs}

During the oviposition period, the spider female deposited an average of $1.5 \mathrm{egg}$ sacs, each contained 34.3 eggs in average (Table 2). Incubation period of both spider female and male averaged 7.3 days at $30 \pm 2 \mathrm{C}$ and $50-60 \%$ R.H.

\section{Adult longevity}

The longevity of the spider female was shorter about one day (14 days) compared with that of male which averaged 15.7 days(Table 3). During adult longevity, spider female consumed about 348.1 preys; this value increased in case of spider male; its food consumption was 365.7 preys/ male.

\section{Life cycle}

Table 3 showed that spider female life cycle durated 52.6 days being longer than that of male (47.8 days).The female spiderling consumed about 597.5 preys during its life cycle; while male had the more food consumption(649.1 preys).

\section{Life span}

As shown in table 3 , the spider female life span durarted 66.6days; while that of male was 63.5 days. During this period, the spider female consumed about 995.5 preys /female; this value increased to 1014.8 prey /male. The food consumption depends on both spiderlings and adult stage. The spider male consumed greater number of prey individuals than female.

Table (1): Spiderlings duration and food consumption of the spider Oecobius tembli female and male when fed on the newly hatched larvae of $S$. littoralis at $30 \pm 2 \mathrm{C}^{\circ}$ and $70 \pm 5 \%$ R.H

\begin{tabular}{|c|c|c|c|}
\hline $\begin{array}{l}\text { Spider } \\
\text { stages } \\
\end{array}$ & Sex & $\begin{array}{c}\text { Average } \\
\text { duration in days }\end{array}$ & $\begin{array}{l}\text { No. of devoured } \\
\text { prey individuals }\end{array}$ \\
\hline \multirow[t]{2}{*}{$1^{\text {st }}$ spiderling } & 오 & $8.4 \pm 0.52$ & $78.4 \pm 4.79$ \\
\hline & $\delta$ & $8.4 \pm 0.52$ & $66.3 \pm 3.89$ \\
\hline \multirow[t]{2}{*}{$2^{\text {nd }}$ spiderling } & 오 & $9.9 \pm 0.88$ & $101.1 \pm 7.52$ \\
\hline & 0 & $9.4 \pm 0.52$ & $96.2 \pm 10.68$ \\
\hline \multirow[t]{2}{*}{$3^{\text {rd }}$ spiderling } & $q$ & $15.9+0.88$ & $256.5 \pm 20.73$ \\
\hline & $\hat{\partial}$ & $14.6 \pm 0.70$ & $266.6 \pm 17.1$ \\
\hline \multirow[t]{2}{*}{$4^{\text {th }}$ spiderling } & 웅 & $6.6 \pm 0.84$ & $126.1 \pm 43.36$ \\
\hline & $\delta$ & $5.4 \pm 0.52$ & $139.8 \pm 15.74$ \\
\hline \multirow[t]{2}{*}{$5^{\text {th }}$ spiderling } & o & $4.5 \pm 0.53$ & $84 \pm 11.57$ \\
\hline & 0 & $2.7 \pm 0.48$ & $80.2 \pm 12.93$ \\
\hline \multirow[t]{2}{*}{ Total spiderling } & 운 & $45.3 \pm 2.45$ & $597.5 \pm 170.59$ \\
\hline & $\hat{\sigma}$ & $40.5 \pm 1.18$ & $649.1 \pm 27.69$ \\
\hline \multirow{2}{*}{\multicolumn{3}{|c|}{$\begin{array}{l}\text { L.S.D. } 0.05 \\
\text { for immatures food consumption }\end{array}$}} & $9 \quad 58.6$ \\
\hline & & & 30.28 \\
\hline
\end{tabular}


Table (2): Adult female longevity and fecundity of Oecobius tembli when fed on the $S$. littoralis newly hatched larvae at $30 \pm \mathrm{C}^{\circ}$ and $70 \pm 5 \%$ R.H.

\begin{tabular}{lcc}
\hline \multicolumn{1}{c}{ Biological aspects } & $\begin{array}{c}\text { Duration } \\
\text { (day) }\end{array}$ & $\begin{array}{c}\text { Food consumption } \\
\text { prey/spiderling/day }\end{array}$ \\
\hline Pre-ovipostion & $3.5 \pm 0.53$ & $114.3 \pm 9.19$ \\
\hline Ovi-postion & $4.5 \pm 0.53$ & $128.0 \pm 11.35$ \\
\hline Post- ovipostion & $6.0 \pm 0.82$ & $105.8 \pm 16.67$ \\
\hline Number of egg sacs/female & $1.5 \pm 0.55$ & - \\
\hline Total number of eggs/Sac & $34.3 \pm 4.5$ & - \\
\hline
\end{tabular}

Table (3): Duration of different stages of Oecobius tembli female and male when fed on $S$. littoralis newly hatched larvae $30 \pm 2 \mathrm{C}^{\circ}$ and $70 \pm 5 \%$ R.H.

\begin{tabular}{|c|c|c|c|}
\hline $\begin{array}{c}\begin{array}{c}\text { Biological } \\
\text { aspects }\end{array} \\
\end{array}$ & Sex & $\begin{array}{c}\text { Duration } \\
\text { (day) }\end{array}$ & $\begin{array}{l}\text { Food consumption } \\
\text { prey/spiderling/day }\end{array}$ \\
\hline \multirow[t]{2}{*}{ Life cycle } & $q$ & $52.6 \pm 2.46$ & $597.5 \pm 170 \pm 59$ \\
\hline & 0 & $47.8 \pm 1.18$ & $649.1 \pm 27.69$ \\
\hline \multirow[t]{2}{*}{ Adult longevity } & $\underline{9}$ & $14 \pm 0.82$ & $348.1 \pm 27.27$ \\
\hline & $\delta$ & $15.7 \pm 2.3$ & $365.7 \pm 81.17$ \\
\hline \multirow[t]{2}{*}{ Life span } & $q$ & $66.6 \pm 2.83$ & $995.5 \pm 40.8$ \\
\hline & 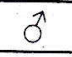 & $63.5 \pm 1.78$ & $1014.8 \pm 82.43$ \\
\hline \multicolumn{4}{|l|}{ L.S.D. 0.05} \\
\hline \multirow[t]{2}{*}{ For Life cycle } & 운 & 2.70 & \\
\hline & $\delta$ & 1.9 & \\
\hline \multirow[t]{2}{*}{ For Longevity } & 9 & 1.03 & . \\
\hline & $\delta$ & 4.60 & \\
\hline \multirow{2}{*}{$\begin{array}{l}\text { For longevity of } \\
\text { food consumption }\end{array}$} & $q$ & 58.16 & \\
\hline & 0 & 30.28 & \\
\hline
\end{tabular}

\section{Life table paramcíers}

The effect of food type on net reproductive rate $\left(R_{0}\right)$ of the spider reached 5.65 times. The generation time $(\mathrm{T})$ was 58.55 days. Increased rate in life table divided into two types; the first namely intrinsic rate of natural increase $\left(\mathrm{r}_{\mathrm{m}}\right)$ had the capacity to increase 0.03 individual female/day which the finite rate of increase was $\exp _{\mathrm{rm}} 1.03 /$ times/female/day and the time of generation doubling (DT) was 23.1days.

\section{REFERENCES}

Dick Jones .1983. The country life guide to spider of Britain and northern Europe. Country life books $320 \mathrm{pp}$.

Dinter, A. 2004. A mass rearing method for the linyphiid spider species Erigone atra (Blackwall) (Araneae: Linyphiidae). J. Appl. Entomol., 128 (3): 200-203.

El-Erksousy, M. H. 2000. Studied on some spiders in Egypt .Ph.D. Thesis, Fac. Agric., Al-Azhar Univ., 130 pp.

El-Erksousy, M. H. 2003. Biology of the spider Theridion egyptium Fawzy \& El-Erksousy fed on Spodoptera littoralis larvae. Bull. Ent. Soc. Egypt, 80:229-233.

El-Erksousy, M. H. and Amer, R. M. 2007. Biological and predation studies on the predaceous spider, Steatoda triangulosa (Walckenaer) fed on the pink bollworm, Pectinophora gossypiella (Saund.). Egypt, J. Agric. Res., 85 (5): 1599-1611.

El-Erksousy, M. H.; Ameira Shoeib M. and Wafaa, Gomaa O. 2006. Biological of the spider, Steatoda triangulosa (Walckenare) fed on larvae of Spodoptera littoralis (Boisd). $2^{\text {nd }}$ Conf., On Farm. I.P.M. 16-18. Jan.,:256-259.

Hussein, A. M.; Hassan, M. F. and Ahmed; N. F. R. 2003. Biological aspects of Anelosimus aulicus (C.L. Koch, 1838) (Arachnida: Araneida: Theridiidae) in Egypt. Serket, 8 (4): 129-134.

Levy, G.1998. Fauna Palestine. Arachnidae, Araneae: Theridiidae. The Israel academy of sciences and Humanities. 225 pp.

Levy, G. and Amitai, P. 1981.The spider genus Enoplogntha (Araneae : Theriidae) in Israel. Zool. J. Linn. Soc., 72:43-67.

Putman, W. L. 1967. Life histories and habits of two species of Phlodromus (Araneid: Philodromidae) in Ontario. Can. Entomol., 99: 622-631.

Riechert, S. E. and Lockley, T. 1984. Spiders as biological control agents. Ann. Rev. Entomol., 29:29-32. 